\title{
What Do Freshmen Really Know about Research? Assess before You Teach
}

\author{
Jean Caspers \\ Linfield College \\ Steven Mark Bernhisel \\ Linfield College
}

Follow this and additional works at: https://digitalcommons.linfield.edu/librariesfac_pubs

Part of the Educational Assessment, Evaluation, and Research Commons, and the Library and Information Science Commons

\section{DigitalCommons@Linfield Citation}

Caspers, Jean and Bernhisel, Steven Mark, "What Do Freshmen Really Know about Research? Assess before You Teach" (2005). Faculty \& Staff Publications. Accepted Version. Submission 7.

https://digitalcommons.linfield.edu/librariesfac_pubs/7

This Accepted Version is protected by copyright and/or related rights. It is brought to you for free via open access, courtesy of DigitalCommons@Linfield, with permission from the rights-holder(s). Your use of this Accepted Version must comply with the Terms of Use for material posted in DigitalCommons@Linfield, or with other stated terms (such as a Creative Commons license) indicated in the record and/or on the work itself. For more information, or if you have questions about permitted uses, please contact digitalcommons@linfield.edu. 


\title{
What Do Freshmen Really Know About Research? Assess Before You Teach
}

\author{
Jean Caspers and Steven Mark Bernhisel
}

\begin{abstract}
The paper describes an effort to assess the information literacy skills of entering first year college students. An instrument was developed and information was gathered on students' experience and comfort in conducting library research as well as their perceived competence with specific information literacy skills. In addition students completed a skills test to assess specific knowledge and skills relating to information literacy. Entering freshmen generally self-reported their skills to be less than "excellent". This finding was supported by the results of the skills test. Strengths and weaknesses in information literacy skills are reported as well as implications for librarians who assess and teach these skills to students.
\end{abstract}

\section{Introduction}

An awareness of students' prior knowledge is essential for helping teachers to provide experiences to further develop student understanding. The educational theorist Ausubel (1968) claimed that the "...most important single factor influencing learning is what the learner already knows. Ascertain this ... and teach him accordingly" (Preface Note). Like others who provide college instruction, librarians need an awareness of the concepts, skills, and confidence that students bring to the work of acquiring information. Since librarians often teach as guest lecturers in other faculty's classes for only a few short sessions per course, the opportunity to accurately assess the prior relevant knowledge of students in each class is rare. A librarian can quickly scan for a sense of the situation by asking students about their past experiences or comfort levels with various types of information resources. Common sense would indicate that the resulting show of hands or verbal responses cannot be assumed to be a satisfactory substitute for more in-depth assessment.

Research supports that common sense judgment. For instance, Geffert and Christensen (1998) conducted a survey of 521 incoming St. Olaf College students on both a short test of basic library skills and questions about students' prior experiences and attitudes about libraries, research paper experiences in high schools, and comfort levels with various library resources. Finding no significant correlation "... between selfconfidence and knowledge of several basic library concepts..." they concluded that their results drew "...into question the premise that we can base assessments of student research competencies upon students' professed skills” (p. 283). Students who are confident about their basic computer skills may also assume they are competent with library research involving the use of computers, but in a survey of 66 first-year 
community college students about their information and computer literacy, Profeta and Kendrick (2002) found that "...students considered their basic computer skills to be average to excellent, but their skill in locating, evaluating, and using information via electronic resources revealed a great need for improvement” (p. 39). O'Hanlon (2002) who tested 57 freshmen at Ohio State on Internet tools, search skills, and research techniques, reached a similar conclusion. She found that "... only $9 \%$ of the 43 new freshmen taking the test at orientation achieved a passing score of $70 \%$ on the entire test. None achieved the level normally defined as proficient (80\%)." She concluded that college personnel "...must not assume that new students arrive with acceptable computing and research skills simply because students tell us that they are competent" (p. 63). In another study by Maughan (2001), more than 600 graduating UC Berkeley seniors were asked to self rate their library knowledge and skills and to complete a skills assessment. Maughan reported that "over half of the respondents (and in some cases as high as ... 77\% of the respondents) self-assessed their skills as either "Excellent" or "Pretty Good." In no case during the five-year span of the study did more than 14 percent of the graduating seniors studies self-rank their skills as "Pretty poor." However, "...from $35.5 \%$ to $81 \%$ of the respondents actually received poor or failing scores (defined as a score of $65 \%$ or lower) on the survey questions..." (p. 77). The study concluded that the "...most fundamental conclusion that can be drawn from the Univ. of California-Berkeley Teaching Library surveys is that students think they know more about accessing information and conducting library research than they are able to demonstrate when put to the test" (p. 83).

Here at Linfield College, librarians have developed an instructional presence in the writing intensive course called the Inquiry Seminar (IQS), which is required of all incoming students. Most students complete an IQS during their freshman year, although some transfer students must also take the course. These courses require that students complete a research paper including a library component. IQS courses are taught by professors from across the college's departments. Each professor teaches his or her section on a personally compelling theme. Over the past ten years, IQS course titles have included the Arthurian Legend, the Journals of Marie Bashkirtseff, the Ethics of Business, Economics as the Dismal Science, Paris in the New Century, the Splendors of Asia, Living with Grief and Loss, Science as a Candle in the Dark, Women's Suffrage, Issues of Free Speech, Free to be Foolish, Awakening Creativity, and many others. A librarian is involved with each class, tailoring the research instruction to specific projects or papers assigned, and teaching from one to eight sessions, depending on the arrangements made with the course instructor. At Linfield College, the library's instruction team has articulated a set of core learning goals for students at three levels: as freshmen (Appendix A), as they enter their major fields, and as they complete their senior capstone experiences. Within the context of each IQS course, in more or less depth depending on the time allocated for this work by each of the IQS instructors, Linfield librarians cover such topics as searching techniques in databases and the open Web; retrieval of the sources cited; evaluation of information resources for authority, accuracy, currency, bias, and relevance to the information needed by the student; and use of appropriate reference citations in order to credit authors and avoid plagiarism. While it is evident that the development of skills in these areas is necessary to student success with 
research in college, prior to this time, the assessment of students' incoming understanding and skills had been informal. For this reason, a formal assessment tool was developed to collect information about entering students' prior knowledge and skills relating to information literacy.

\section{Methodology}

\section{Survey Instrument}

It was our desire to produce an instrument to gather the following information:

1. General demographic information about students.

2. Students' perceptions of their overall comfort and skill in gathering information.

3. Students' background in gathering information using library and web-based resources.

4. Students' perceptions of their ability to use specific information literacy skills and knowledge.

5. Students' actual skills and knowledge relating to information literacy.

The process of developing our instrument included a review of published surveys of other college student populations (Geffert \& Christiansen, 1998; Profeta \& Kendrick, 2002; Dunn, 2002). Initial drafts of the survey instrument were not replications of previously published surveys, however the work of other researchers was consulted to gather ideas for the content and organization of our instrument. The draft was pilot tested with a group of our library work-study students who supplied us with feedback to improve the quality of the instrument. We analyzed the results of their completed skills tests to determine whether the information we gained was, indeed, the type of data that we hoped to obtain. Finally, the team of Linfield reference librarians was consulted to evaluate the clarity of the content of the instrument, and to make additional suggestions for gathering data they would find of use. Based on the feedback of the librarians and students, modifications were made to the instrument before it was ready to be administered to the 2003 entering class at Linfield College.

The completed instrument consisted of the following three components:

1. Four demographic questions that were followed by seven questions asking students to identify experiences and attitudes about library research and online searching (Appendix B).

2. Twenty questions asking students to rate their own proficiency in information literacy skills (Appendix C).

3. Twenty one questions (a skills test) to assess students' knowledge and skills relating to the gathering of information (Appendix D). 
In addition to their correspondence with Linfield College library's information literacy competencies for first year students, the skills test questions fit loosely into the rubric of the Association of College and Research Libraries (ACRL) Standards. Six questions correlate with Standard 1 (identify types \& formats of information sources); seven with Standard 2 (develop research strategies, utilize tools to focus search \& identify citation elements and document references); seven with Standard 3 (select and evaluate information); and one with Standard 5 (familiarity with legal \& ethical issues relevant to information literacy).

Table 1: Correlation of Skill Test Questions to the ACRL Information Literacy Competencies

\begin{tabular}{|l|l|}
\hline ACRL Information Standards & Skills Test Numbers \\
\hline $\begin{array}{l}\text { Standard 1: Identify types \& formats of information sources; } \\
\text { exhibit appropriate expectations of their content }\end{array}$ & $1,2,3,4,5,6$ \\
\hline Standard 2: Develop research strategies & $7,8,9$ \\
\hline Standard 2: Utilize tools and focus search & $10,11,12$ \\
\hline Standard 2: Identify citation elements; document references & 13 \\
\hline Standard 3: Select and evaluate information & $15,16,17,18,19$, \\
\hline $\begin{array}{l}\text { Standard 5: Exhibit familiarity with relevant legal \& ethical } \\
\text { issues }\end{array}$ & 14 \\
\hline
\end{tabular}

\section{Study Population and Data Collection}

The completed Linfield College Information Literacy Survey was administered in the Fall of 2003 to 246 members of the entering class at Linfield as part of their incoming student orientation activities. The survey was administered to participants two days prior to the start of the fall semester in an effort to determine which information related knowledge and skills students brought with them as they entered college. The participants were informed that their identities would be kept confidential, their responses would never be linked with their names and that the purpose of the study was to learn more about the information gathering needs of incoming students so we could provide 
appropriate instruction to meet those needs. $54.2 \%$ of the entering freshmen class volunteered to participate in this study. This group closely represented the entire entering freshman class both in terms of gender and choice of major. $58.1 \%$ of the participants were female and were entering college directly from high school. Of the students surveyed, $93.1 \%$ were 18 years old, while the remainder $(6.9 \%)$ were 19 years old. Within the participant group the mean high school GPA was 3.65 (as compared with 3.54 for the entire entering class). The largest group included students who were considering majors in the Social \& Behavioral Sciences 37.8\% (93), followed by the Sciences 31.3\% (77) and undecided majors $19.5 \%$ (48). Only $11.4 \%$ (28) survey participants planned to major in the Humanities.

\section{Data Analysis}

Information from the completed surveys were scored, and derived data was later coded and analyzed using the Statistical Package for the Social Sciences (SPSS). Descriptive statistics, $t$-scores, and Pearson correlation coefficients were compiled from the collected data.

\section{Results}

\section{Student Self-Rating of Skills}

Most students rated their information literacy skills as "good" (between the "fair" and "excellent" categories.) Of the respondents, 62.2\% judged their library skills as "good". This compares with $16.7 \%$ who judged their skills to be "excellent," $19.5 \%$ who selected "fair," and 1.6\% who judged their library skills to be "poor."

Similar results were found with students who rated their skills at "finding information on the World Wide Web" when writing a research paper. The highest number judged their Web skills to be "good" (56.5\%), while $27.2 \%$ selected "excellent," $15.4 \%$ selected "fair," and less than $1 \%$ felt their Web skills were "poor."

When asked to report their comfort level in doing library research, 25.6\% of students said that they were "very comfortable" in doing library research. This compares with the $66.3 \%$ of students who were "fairly comfortable" and $8.1 \%$ who were "fairly" or "very" uncomfortable in doing library research.

In addition to asking entering freshmen to judge their information literacy skills globally, students were also asked to evaluate their ability to use information using specific information literacy skills. Students rated their skills in twenty different areas such as "the use of Boolean operators" and the ability to "evaluate sources for the reliability of the information" (Appendix C).

Students most commonly judged their proficiency to be "good" in ten of the twenty different skills assessed on the instrument. Students felt their skills were "excellent" in two areas ("finding library books by subject or topic" and "knowing why copyright laws are used to protect authors"). Students most commonly judged their skills 
to be "fair" in seven of the skills. These seven areas consisted mainly of skills required to conduct online searches for information.

When asked to judge their "awareness of whether or not downloading music from the web was legal," the same number of students selected "fair" and "good".

Students use the World Wide Web as their primary source of information when writing research papers. The Web was reported as the primary source of information when writing papers by $69.9 \%$ of students. Books (15\%), reference books $(17.5 \%)$, periodicals $(1.2 \%)$, and journals $(1.2 \%)$ were also listed as chief sources of information. (*Note some students selected more than one response and thus the totals exceed $100 \%$ ).

Of the entering freshmen, $42.2 \%$ said that the information literacy skills that they possessed were primarily "self-taught." Librarians were credited with teaching these skills by $32.1 \%$ of students surveyed. Approximately one quarter $(26.0 \%)$ of the students said that they learned information literacy skills from their classroom teachers, while "other" sources were reported by $5.3 \%$ of the students.

\section{Results of Skills Test}

The majority of students judged their information literacy skills to be "good". Students answered correctly an average of 15.2 out of 21 questions ( $72.4 \%$ correct) on the information literacy skills test. The total score on the skills test varied from a high of $100 \%$ of the questions answered correctly to a low of just $19 \%$ of the questions correctly answered.

Table 2: Number \& Percentages of Students Scores by \% Range of Correct Answers on the Skills Test.

\begin{tabular}{|l|l|l|}
\hline Range of correct scores & $\begin{array}{l}\text { Percentage of students } \\
\text { scoring within range }\end{array}$ & $\begin{array}{l}\text { Number of students } \\
(\mathrm{N}=246)\end{array}$ \\
\hline $90 \%$ to $100 \%$ & $3.7 \%$ & 9 \\
\hline $80 \%$ to $89.9 \%$ & $17.9 \%$ & 44 \\
\hline $70 \%$ to $79.9 \%$ & $39.8 \%$ & 98 \\
\hline $60 \%$ to $69.9 \%$ & $18.7 \%$ & 46 \\
\hline Below $60 \%$ & $19.9 \%$ & 49 \\
\hline
\end{tabular}

\section{Significant Relationships and Differences}

There were three significant relationships between students' "Total Score" on the information literacy skills test and self-reported student characteristics. The relationship between "Total Score" and students' grade point average was significant ( $r=.242$ $p<.001)$. This indicates that the higher a student's grade point average, the greater the likelihood of scoring higher on the information literacy skills test. In addition there was a significant but weak correlation between "Total Score" and students' comfort level in doing library research $(r=.194 p=.002)$ as well as between "Total Score" and students" rating of their library skills $(r=.156 p=.014)$. 
There was no significant correlation between a student's "Total Score" and his or her self-reported skill at finding information on the World Wide Web. Similarly, no significant relationship could be found between "Total Score" and the number of research papers students had written in their senior year of high school. There was also no correlation between "Total Score" and student self-reported frequency of library use.

Males and females had significantly different grade point averages, $(t=5.68$ $\mathrm{p}<.001$ ) with females reporting a mean GPA of 3.75 and males reporting a mean GPA of 3.52. There was also a significant difference between the scores of males and females on the skills test with female students scoring higher than their male counterparts $(t=2.01$ $\mathrm{p}=.046$ ). Females did not rate their comfort or skill in finding information to be any higher than males did, and there was no significant difference between male and female students' perceptions of their library skills, Web skills, and comfort in doing library research.

\section{Discussion}

The statistically significant correlations between various factors and the results of the skills tests in this study were compared to the findings of other researchers in this field. The students in this study who reported more comfort in doing library research tended to do better on the skills test. These results support those of Kunkle, Weaver \& Cook (1996), who found a correlation between low scores and student discomfort with library research, but differ with Geffert and Christensen (1998), who found no statistically significant correlation between comfort levels in libraries and student scores on a skills test. Like Geffert and Christensen (1998), this study found a significant correlation between score on the skills test and student GPA. The higher the student's grade point average from high school, the higher he or she was likely to score on the skills test. The Linfield College study results also appeared to confirm the findings of Geffert and Christensen (1998) regarding gender related differences: female students as a group reported higher grade point averages than males, and females scored significantly higher on the skills test. However, females did not self-assess their library or Web skills or their comfort in doing library research to be any higher than males did.

The results of the statistical analysis showed a significant but weak correlation between students' total score on the skills test and their rating of their own library skills, although there was not a significant correlation between total scores and self-rated search effectiveness on the World Wide Web. Most Linfield students perceived their library skills as "good," and although the majority reported that their primary research source is the World Wide Web, only a little more than a quarter of the students judged their ability to find information on the Web to be "excellent." This differs from all four studies reviewed for this project which assessed students' perceptions of their abilities and tested them on related skills. In each of the other studies, no significant correlations between student self-assessment of their research skills and their tested skills were found (Geffert \& Christensen,1998; Profeta \& Kendrick, 2002; O'Hanlon, 2002; Maughan, 2001). While those researchers tended to conclude that students report themselves to be more adept with information literacy skills and concepts than they appear to be when tested, this study concludes that incoming Linfield College students were more likely to report their skills at levels similar to the levels at which they tested. It therefore appears that 
while the subjects in this study have some confidence in their general information literacy skills, they nevertheless feel that their skills and confidence in performing these tasks are not complete. Based on the skills test results, their insights seem realistic.

For this study we assessed students' information literacy skills using a short multiple-choice skills test during their orientation weekend as incoming college freshmen. Our goal was to determine the degree to which first year college students possessed essential information literacy skills that would be required of them as they began the first years of their college career. It is apparent that these skills were tested apart from their application in a real-world scenario. The real abilities of neither the highest scoring students nor those who failed this test could be fully judged through a multiple-choice survey. David P. Ausubel (1968) wrote: "It is obviously one thing to acquire a concept and quite another to use it in ... learning related new meanings, and in solving problems" (p. 509). Can a multiple-choice test provide an authentic assessment of the capability of a student to put all the pieces (skills) together to construct a useful set of information to support academic work? Perhaps not, but an objective, short-answer test such as the skills test used in this study is manageable and affordable given the resources of a small institution when an assessment of the information literacy attitudes and skills of a large group of entering class of students is desired. Although this type of assessment may not give a complete picture of students' abilities in practice, the resulting data does have some utility when used to survey a large group of students to gain a broad view of their skills.

Most students in this group had no trouble identifying information formats (books, journal articles, Web pages) from citations. A majority of them were able to select the search string most likely to be effective for a topical search from a list of possibilities. When asked to select the best group of synonyms for a search term, most of the students were successful. Almost all of the students were able to correctly ascertain the currency of a Web page with an "update date" displayed on the page.

Students reported that they did not frequently look beyond the Web for major information resources for research. Half of the students in this group were not sufficiently familiar with the concept of scholarly journals to differentiate between scholarly and popular journals based on a short list of periodical titles. Many to most did not make good choices in selecting the appropriate type of databases to search for books versus periodical articles.

About one third of the students needed help with the concepts of truncation and wildcards. Over one quarter had misconceptions about the application of copyright laws in the educational environment as it affects student work. More than half were not able to recognize the type of source identified by a Web URL (educational, governmental, organizational, commercial, personal).

Although most respondents recognized that terms in a subject field are useful as terms for further topical searching in a database, nearly one quarter of them needed to learn more about when to begin with the subject field in a database search. More students were able to identify the likely effect of a search statement including a Boolean operator than were able to correctly define the term Boolean given a choice of definitions.

When asked to indicate all the applicable ways (of three possibilities given) to find out more about the creators of a Web site, most of the students correctly identified 
"Click on About Us" but only one third also chose "Click on Home," and only 13\% included "Back up in the URL one backslash at a time to examine the context of the page" as a correct answer to include. Only 5.7\% correctly responded that all three of these answers applied as responses to the task of finding out more about a site's authorship.

Table 3: Summary of Students' Strengths and Weaknesses in Selected Information Literacy Skills and Experiences (based on skills test plus self-rating survey).

\begin{tabular}{|c|c|}
\hline Stronger Areas & Weaker Areas \\
\hline & $\begin{array}{l}\text { Selecting the appropriate databases to } \\
\text { retrieve format types (i.e. books v.s. } \\
\text { periodical articles). } \\
\text { - } 74 \% \text { identified the appropriate resource } \\
\text { type to locate periodical articles by topic, } \\
\text { but only } 42 \% \text { selected the appropriate } \\
\text { database type to locate a book held within } \\
\text { the library. (Skills Test) }\end{array}$ \\
\hline & $\begin{array}{l}\text { Identifying scholarly journals. } \\
\text { - } 54 \% \text { correctly identified scholarly } \\
\text { journals from a list of periodicals. }\end{array}$ \\
\hline $\begin{array}{l}\text { Identifying formats (books, articles, Web } \\
\text { sites) from citations. } \\
\text { - } 86 \% \text { could correctly identify the } \\
\text { bibliographic record of a book, } 85 \% \text { a } \\
\text { periodical article, and } 97 \% \text { an Internet } \\
\text { citation. (Skills Test) }\end{array}$ & $\begin{array}{l}\text { Using sources beyond the Web as "major } \\
\text { information resources" for research. } \\
\text { - } 70 \% \text { reported the Web as their primary } \\
\text { source of information as compared with } \\
\text { fewer than } 18 \% \text { listing books or } \\
\text { periodicals as major sources. (Self- } \\
\text { rating survey) }\end{array}$ \\
\hline $\begin{array}{l}\text { Identifying the utility of the subject field } \\
\text { when examining a library catalog's } \\
\text { bibliographic record. } \\
\text {-92\% of respondents identified the subject } \\
\text { field display as useful to find more } \\
\text { references on a similar topic from a } \\
\text { bibliographic record (Skills Test) }\end{array}$ & $\begin{array}{l}\text { Choosing the subject field in a database as } \\
\text { a search entry option when initiating a } \\
\text { search. } \\
\text { - } 74 \% \text { identified the appropriate use of a } \\
\text { subject field in a database as a starting } \\
\text { point for a search on a topic. (Skills Test) }\end{array}$ \\
\hline \multirow[t]{2}{*}{$\begin{array}{l}\text { Basic search techniques } \\
\text { - } 87 \% \text { identified the most appropriate } \\
\text { keywords to perform an Internet search } \\
\text { on a given topic. } \\
\text { - } 85 \% \text { selected appropriate synonyms for } \\
\text { conducting searches.) } \\
\text { - } 87 \% \text { correctly identified the effect of a } \\
\text { given Boolean search string } \\
\text { (Skills Test) }\end{array}$} & $\begin{array}{l}\text { Advanced search techniques. } \\
\text { - } 63 \% \text { recognized the effects of a search } \\
\text { using a wildcard and truncation. (Skills } \\
\text { Test) }\end{array}$ \\
\hline & Citing information to avoid plagiarism \\
\hline
\end{tabular}




\begin{tabular}{|l|l|}
\hline & $\begin{array}{l}\text { 72\% knew when it was necessary to } \\
\text { cite their sources of information } \\
\text { (Skills Test) }\end{array}$ \\
$\begin{array}{l}\text { 74\% identified commonly used } \\
\text { citation styles in academic writing. } \\
\text { (Skills Test) }\end{array}$ \\
\hline & $\begin{array}{l}\text { Evaluating Sources (Web-based resources) } \\
\text { 43.1\% correctly matched the results of an } \\
\text { Internet search with the type of authorship } \\
\text { (educational, commercial, organizational, } \\
\text { personal, etc.) that most likely sponsored } \\
\text { the listed Web pages, based on the URLs in } \\
\text { the results list. (Skills Test) } \\
\text {-6\% correctly selected all of the possible } \\
\text { ways (from a short list of possibilities) to } \\
\text { learn more about the authors of a Web } \\
\text { page. (Skills Test) }\end{array}$ \\
\hline
\end{tabular}

\section{Implications for Teaching}

Based on the strengths and weaknesses identified, the following suggestions for refocusing instructional practices for information literacy with first-year students emerged.

Most of our incoming students were able to discern between book, article and Web site citations but less likely to recognize which items were scholarly. Most students demonstrated basic search skills likely to assure they would find plenty of Web based resources, but they were less likely to know how to approach the evaluation of the type of source or the credibility of the creators of each site from either a list of search results or from the face of a Web site. For these reasons critical thinking, including focusing on the authority behind the information and other aspects of evaluation should be emphasized when discussing the selection and use of resources.

Since participants in the study were strong in identifying appropriate search terms, synonyms, and alternative words for searching, but were weak at utilizing sources beyond the Web and at selecting appropriate databases, focus should be on the nature of research databases and their contents more than on the basics of entering a search.

Since most of the students surveyed were able to identify the effect of a simple Boolean search but were not familiar with the use of truncation or wildcards, emphasis should be placed on enhancing the basic search skills most students have probably developed using web browsers before coming to college.

A quarter of the students were unclear about when it was necessary to cite their sources, therefore the use and attribution of resources should be emphasized.

\section{Conclusions}

Student self-reporting of skills has some value, but is not in itself sufficient as an assessment method. Most students in this study indicated they believed their information literacy skills were good, but were aware of their need to further refine their information 
literacy skills in order to succeed in college. It was interesting to note the tendency for women to self-assess their skills at a similar level to men although the women scored significantly higher on the skills test. Although the data collected in this study does not indicate whether the women were underestimating their skills or the men were overestimating theirs, relying on the self-assessments alone may have lead to an assumption that the men's skills as a group were higher than the women's, whereas they were, in fact, lower when tested. It is important, therefore, for librarians to balance selfassessment feedback from students with some form of individualized assessment. Assessment should, of course, be followed by opportunities for students who need additional help to get it, whether through online tutorials designed for this purpose, via individualized consultations with librarians in their offices or at the reference desk, or, perhaps ideally, through collaboration with teaching faculty for deep integration of information literacy instruction into the curriculum.

Although students reported that during their high school years library and Web research skills were mainly self-taught, most of them appeared to be aware that they needed to learn more. One could therefore infer that most incoming first year students would be open to guidance in their information gathering activities for college courses in order to elevate their information literacy skills to the more sophisticated level necessary for success in scholarly work. This study identified some foundational information literacy skills these students have gained prior to college. The results in terms of relative strengths and weaknesses within the skill sets of these students may not be directly applicable to student populations at other institutions or, indeed, over the coming years at Linfield College. However, this research suggests that an assessment of students as they begin their first year of college can be useful in identifying both their perceived as well as their actual skills with information literacy. This information can prove to be useful as librarians provide instructional experiences to enhance students' information literacy skills. 


\section{REFERENCES}

Ausubel, D. P. (1968). Educational psychology: A cognitive view. Troy, MO: Holt, Rinehart \& Winston.

Dunn, K. (2002). Assessing information literacy skills in the California State University: A progress report. Journal of Academic Librarianship, 28 (1), 26-35.

Geffert, B. \& Christiansen, B. (1998). Things they carry: Attitudes toward, opinions about, and knowledge of libraries and research among incoming college students. Reference \& User Services Quarterly, 37(3), 279-289.

Kunkel, L.R., Weaver, S.M., \& Cook, K N. (1996). What do they know? An assessment of undergraduate library skills. Journal of Academic Librarianship, 22(6), 430-35.

Maughan, P. D. (2001). Assessing information literacy among undergraduates: a discussion of the literature and the University of California-Berkeley assessment experience. College \& Research Libraries 62(1), 71-85.

O'Hanlon, N. (2002). Net knowledge: Performance of new college students on an Internet skills proficiency test. Internet and Higher Education 5(1), 55 - 66.

Profeta, P. \& Kendrick, M. (2002). Information literacy skills of community college freshmen. Visions: The Journal of Applied Research for the Florida Association of Community Colleges, 3(1), 35-41. 